\title{
El uso de la comunicación persuasivo-seductora en el proceso de adaptación al plan Bolonia: fundamentos metodológico-emocionales para la asignatura Historia de los medios audiovisuales
}

\author{
Antonio Cantos Ceballos \\ Universidad de Málaga \\ cantos@uma.es
}

\begin{abstract}
Resumen
De acuerdo con los últimos descubrimientos en el campo de las neurociencias en los que los canales del verdadero conocimiento humano se centran en el trazado de vías neuronales y sinapsis, buscamos la estimulación del cerebro emocional de nuestros alumnos (seeking) mediante el desarrollo de actividades integradoras, en las que emoción y razón interaccionan, consiguiendo que conviertan en objeto de deseo aquello que se pretende que sea objeto de conocimiento. Para ello, optamos por un sistema de intervención docente autopoiético que implica trabajar con componentes didácticos fundamentales, tales como: estilo de enseñanza democrático, estrategia didáctica participativa, complementariedad de los métodos de la inducción y deducción o el uso de técnicas grupales participativas lo que facilita y fomenta en el alumnado su capacidad para investigar, organizar, elaborar y exponer la información de la materia. Concebimos las tutorías como un espacio abierto de intercambio de conocimiento, en el que se activa el componente de aprendizaje emocional del alumno porque lo obliga a la construcción de su conocimiento contribuyendo a su madurez intelectual. Además, a lo largo de todo el proceso descrito, trabajamos la competencia digital de nuestros alumnos fomentando las siguientes capacidades: e-conciencia, alfabetismo tecnológico, alfabetismo digital y alfabetismo mediático
\end{abstract}

Palabras clave: Comunicación persuasivo-seductora; Pedagogía creativa; Historia; Competencia digital

The use of the tempting-seductive communication in the procedure adjusting to Bolonia plan: basics and emocional principles learning the subject History of the media

\begin{abstract}
Recents discoveries in Neurology says the human knowledge is in the sinapsis, responsible to stimulate the brain cells in the emocional brain of the student. This function called seeking encourages the neurotransmitters students and allows them learning this subject thanks to differents creatives strategies that stimulates theirs emocional brains because of the tempting-seductive communication. We choose this pedagogical way in the classroom, called autopoiético course, that helps us to develop the most importants didactic proposals such as: democratic learning, creatives strategies to learn with, rolls playing who allows the students learns to investigate, to organize, and to put forward the differents themes about this subject. We thinks the tutorial class is a perfect scene for an open exchange of knowledge because this way helps the students to be responsible about theirs knowdledge and to permit them reach theirs intelectual develop. So, in this pedagogical syllabus, we works the digital competente and the academic use of social networks, learning with the differents new technologiycal abilities and the media literacy in multiple contexts
\end{abstract}


Key Words: Tempting-seductive communication; Creative pedagogical course; History media; Digital competence.

\section{Referencia normalizada:}

Cantos Ceballos, A. (2013) El uso de la comunicación persuasivo- seductora en el proceso de adaptación al plan Bolonia: fundamentos metodológico-emocionales para la asignatura Historia de los medios audiovisuales. Historia y Comunicación Social. Vol. 18. № Especial Noviembre. Págs. 827-837.

Sumario:1.Introducción. 2. Cerebro emocional, aprendizaje y discurso publicitario. 3. Cinco competencias transversales y un modelo educativo autopoiético. 4. Trabajos académicos dirigidos. 5 . Las tutorías, piedra angular del sistema. 6. Conclusiones. 7. Referencias bibliográficas.

\section{Introducción}

Tras varios siglos en los que el objetivo de la educación era instruir a la población para que sólo unos pocos pudieran acceder a la Universidad, en el siglo XX se generaliza la educación para gran de la población y en el siglo XXI, la información, la cultura y la tecnología están al alcance de casi toda la ciudadanía, ya no es sólo patrimonio exclusivo de las universidades. En este contexto descrito, la educación se orienta hacia el concepto de una educación para todos y a lo largo de toda la vida (Long Life Learning, LLL). Este concepto, impulsado por la UNESCO con el Informe Delors (1996: 38), implica que las nuevas políticas pedagógicas universitarias, se deban fundamentar en cuatro pilares: aprender a conocer, aprender a hacer, aprender a vivir juntos y aprender a ser. Para conseguir dicho aprendizaje de manera integral se atribuyen a la Universidad cuatro funciones esenciales: preparación para la investigación y la enseñanza, la oferta de tipos de formación muy especializados y adaptados a las necesidades de la vida económica y social, apertura a todos para responder a los múltiples aspectos de lo que llamamos educación permanente en el sentido lato del término y la cooperación internacional.

En efecto, como confirma el Plan Bolonia, se ha pasado de una enseñanza para incorporar a los ciudadanos a una sociedad desarrollada, a un aprendizaje para incorporarse a ella, para producir en ella y para disfrutar en ella. En suma, se apuesta por una educación para el desarrollo de la persona de forma individual, y también de forma colectiva que le permita convivir en un mundo multicultural, diverso y en continuo cambio desde la participación activa. Esto supone un cambio radical, una verdadera revolución copernicana en el planteamiento de la acción docente en el aula: pasar de la instrucción de contenidos a la adquisición de competencias, como respuesta directa a las realidades planteadas por el siglo XXI, la sociedad de la información y a la globalización cultural y económica. No es tarea fácil adaptar los viejos programas académicos, centrados en la instrucción de contenidos, hacia el nuevo concepto de la guía docente, en el que se trata de definir y secuenciar todo un proceso 
de conocimientos, habilidades, actitudes, valores y virtudes que garantizan la bondad y eficiencia de un ejercicio profesional responsable y excelente: las competencias.

Pero, más allá de este tema de la adaptación formal apuntado, el verdadero problema en la práctica docente universitaria es la rutina, porque es como una segunda naturaleza que destruye a la primera, como un extintor que apaga la llama. En la comunicación educativa, la rutina es aún más peligrosa, por cuanto puede echar mano de supuestas justificaciones racionales. Hasta ahora, la rutina en la universidad se ha venido justificando por una presunta fidelidad a los contenidos curriculares y a la tradición docente. Pero, sin duda, se confunden los contenidos con la manera específica de comunicarlos, sin caer en la cuenta de que cuando surgieron estas formas de comunicación los destinatarios del proceso de enseñanza eran muy distintos de los actuales. El estilo comunicativo que impera en el ámbito educativo y cultural universitario está a menudo muy alejado de la sensibilidad de las nuevas generaciones. El objetivo último de la comunicación educativa universitaria debe ser la generación de aprendizaje, lo que comporta una gran habilidad mediadora, puesto que se ha de lograr un equilibrio de fidelidades, a los contenidos y a los destinatarios (alumnos). Y estos últimos, como ya hemos comentado, han cambiado sustancialmente, lo que exigirá cambios igualmente sustanciales en el proceso comunicativo en el aula. El aprendizaje ya no puede ser el resultado de un acto aislado, sino el resultado de un proceso, de manera que el docente universitario necesita imperiosamente no sólo tener la capacidad de atrapar la atención de sus alumnos, sino de retenerla: una tarea más que difícil.

En este contexto descrito en el que el docente universitario debe moverse, nuestro éxito como emisor siempre estará condicionado por la respuesta del receptor. Los procesos de enseñanza-aprendizaje, en cuanto que forman parte de la comunicación persuasivo-seductora, sólo cumplen su función si logran provocar cambios en el destinatario, lo que comporta que han de convertirse necesariamente en eje o centro. Más que nunca, hoy, en el aula universitaria, la comunicación es un $90 \%$ de retórica y un 10\% de información: es fundamental la puesta en escena, la transformación de la información en comunicación y la capacidad movilizadora del docente. Es cierto que la sobrevaloración de la función fática en la acción docente puede llevar al contacto sin contenidos, es decir, a la comunicación vacía; pero el descuido de esta función en el discurso educativo puede llevar, paradójicamente, a un idéntico resultado, es decir, a la comunicación vacía de dichos contenidos: el alumno no accede a ellos por falta de interés, es decir, no se implica y no se activan en él los mecanismos que generan el aprendizaje. Somos conscientes de que no sirve para nada una información que no moviliza, que no lleva a la acción, que no provoca un cambio y que no transmite una corriente de acción. Para que los alumnos universitarios del siglo XXI estén dispuestos al sacrificio del esfuerzo, el profesor debe seducirlos con el beneficio del conocimiento. 


\section{Cerebro emocional, aprendizaje y discurso publicitario}

Investigaciones neurológicas con ratones y personas, llevaron a Jan Panksepp al descubrimiento de un área cerebral que denominó seeking, situada en el cerebro emocional, como la responsable de provocar inquietud y excitación. Como explica Guterl (2002: 55), este neurobiólogo observó que, cuando estimulaba esta área cerebral en los ratones, los animales se ponían a olfatear el aire y a dar vueltas buscando algo. Ese algo no era alimento, sino el deseo de algo nuevo. El también neurobiólogo, Mark Solms, siguiendo estas investigaciones, descubrió que este cerebro emocional era el responsable de toda actividad creativa, de motivar la acción y de impulsarla: era la central energética, activadora de apetencias, impulsos, emociones y estados de ánimo que dirigen la conducta de todo ser humano. Ninguna idea puede movilizarnos si no está conectada con dicha central energética, con esta fuente de energía. Porque, además, en los sentimientos emocionales intervienen muchos más mecanismos cerebrales que en los pensamientos. En efecto, las emociones crean una furia de actividad dedicada a un solo objetivo y, como explica J. Ledoux (1999: 337), mediante unos canales de comunicación intercelulares(sinapsis), activan todas las funciones cerebrales relacionadas con el aprendizaje: percepción, memoria, emoción y pensamiento. Tanto los animales como las personas tan sólo nos movilizamos gracias a la energía generada por un cerebro emocional activado, y es el temor al fracaso o la activación del deseo lo que genera la capacidad para educar, para sacar de dentro, para desarrollar o hacer crecer lo que está en el interior del alumno de manera latente y embrionaria.

Esta importancia determinante del deseo en el aprendizaje, establecida a la luz de las últimas investigaciones neurológicas comentadas, choca frontalmente con los déficits notables que en los ámbitos educativos existen en cuanto a la capacidad de creación del deseo. No se sabe cómo cumplir esta función, se dispone de productos de calidad pero no se sabe como venderlos. Y es que, la diferencia fundamental entre el discurso publicitario y el educativo es la diferencia entre la importancia que se le otorga al receptor en uno y otro caso. Mientras en el discurso publicitario está incrustado el receptor-consumidor y hay múltiples indicios de su presencia, en el discurso educativo el receptor-alumno brilla por su ausencia. Una mirada al mundo de la publicidad, nos ofrece una solución: el factor emocional es absolutamente relevante en el mundo del marketing, dado que la sintonización con el posible comprador-receptor es básica. La importancia determinante que la publicidad asigna a las emociones radica en la imperiosa necesidad de activar el deseo del consumidor porque, obviamente, no sirve de nada producir productos si nadie desea adquirirlos. Por esto, precisamente, nuestra sociedad postindustrial consumista se ha convertido en una absoluta cultura del deseo: se incita al deseo y se apremia para que se satisfaga de manera inmediata. Los publicitarios, como creativos del deseo, son tan hábiles en la producción del mismo que las personas sobre las que actúan acaban convencidas de que su deseo es espontáneo y natural, y consiguen que consideren imprescindibles unos productos que son totalmente superfluos. Probablemente, la lección principal que, como profesores, podemos extraer de los publicitarios provenga del análisis de cómo consiguen 
vender las reticencias, indiferencias y rechazos por parte de los receptores, de cómo consiguen atraer su atención hacia unos productos que de entrada no tienen interés alguno para ellos. Como vemos, la comunicación publicitaria, al igual que la educativa, participa de lo que se denomina comunicación persuasivo-seductora, es decir, de un tipo de comunicación destinada a modificar los conocimientos, las actitudes, los valores y las pautas de comportamiento de los receptores. Podíamos incluso decir que existen elementos de conexión entre estos dos universos comunicativos, tales como: las estrategias de persuasión, el carácter imperativo y normativo, la búsqueda de elementos motivadores o la activación y manipulación de deseos.

\section{Cinco competencias transversales y un modelo educativo autopoiético}

El modelo de intervención educativa que proponemos para la adaptación de la asignatura Historia de los medios audiovisuales al entorno EEES, se centra, concretamente, en cinco competencias transversales de las 22 de las que consta el proyecto Tuning (2007), dado el carácter vehicular que guardan las mismas con la esencia del proceso de la comunicación audiovisual y, de manera particular, con la necesidad formativa de los historiadores de la comunicación: capacidad de análisis y síntesis, organización y planificación, comunicación oral y escrita, razonamiento crítico y aprendizaje autónomo.

La elección de la competencia de capacidad de análisis y síntesis responde a la necesidad de incentivar la habilidad del alumno para identificar las partes que forman el objeto de conocimiento y, además, recomponerlo en sus diferentes apartados. Se trata, pues, de ejercitar el aprendizaje para diseccionar el objeto a conocer, mediante la práctica con esta capacidad de carácter instrumental.

Mediante la segunda de las competencias transversales de carácter instrumental elegidas, la capacidad de organización y planificación, pretendemos el ejercicio del alumno en la jerarquización de su conocimiento. Esto supone, en la práctica, que los alumnos aprendan a colocar los elementos cognoscitivos de acuerdo con unos criterios de clasificación y secuenciación, para, de este modo, anticiparse y regularizar sus acciones.

La tercera de las competencias transversales elegidas, también de carácter instrumental, es la capacidad para la comunicación oral y escrita, tarea fundamental en el proceso formativo de los futuros historiadores de la comunicación. Buscamos la capacitación de los alumnos mediante la transmisión adecuada de los mensajes con intención, estimulando la función activa de sentirse activo e integrado en la sociedad.

La cuarta de las competencias transversales y que responde a la modalidad de competencia personal, es el fomento del razonamiento crítico, es decir, la facilidad para argumentar ideas, posiciones y puntos de vista que los alumnos guardan con respecto a un determinado tema. 
La quinta y última de las competencias transversales elegidas participa de la modalidad sistémica y es, concretamente, el aprendizaje autónomo. En la práctica, la práctica con esta competencia implica la toma conciencia de lo que el alumno sabe, de cómo lo aprende y de cómo lo gestiona con una finalidad primordial: satisfacer sus objetivos personales.

El desarrollo eficaz de estas cinco competencias transversales elegidas, precisa de un modelo pedagógico que permita la práctica con las habilidades de saber hacer y de saber ser mediante un oportuno y sistemático desarrollo de tareas creativas que lo permitan. Optamos por una pedagogía del acontecimiento y, consecuentemente, elegimos el modelo autopoiético, vehículo muy apropiado para el fomento de la capacidad autónoma del alumno. De acuerdo con este modelo de intervención autopoiético, el rol presencial del profesor se sitúa en un segundo plano, mientras que el protagonista y artífice principal del mismo es el alumno en una constante interacción de aprendizaje con la asignatura. Esta discreta presencia del profesor apuntada se ve compensada, con creces, por la vital importancia que cobra su acción docente, su capacidad persuasivo-seductora, fundamental en la labor de sugerencias creativas necesarias para estimular y articular esta actitud activa de los alumnos. La docencia, tanto en grupo grande como también en los grupos reducidos, se plantea como un escenario abierto de intercambio de conocimiento, en el que se mixturan las reflexiones del profesor y las propuestas de los alumnos. Este necesario feed-back permanente que se crea en la asignatura activa el componente emocional del alumno y lo obliga a implicarse en la construcción de su propio conocimiento, procesando la información adquirida mediante la expresión de sus ideas y puntos de vista, relacionando permanentemente teoría y práctica, manifestando su capacidad para el análisis y la crítica, ahondando en sus intereses intelectuales y, en suma, construyendo su madurez intelectual.

\section{Trabajos académicos dirigidos}

Como ya hemos comentado, la articulación de la asignatura gira en torno a los trabajos académicos dirigidos en equipos de cinco miembros como máximo y el posterior debate que, a propósito de la puesta en escena del trabajo por el grupo de turno, se suscita. Para el desarrollo de esta propuesta concreta, consideramos necesario la utilización de las técnicas grupales participativas. Dichas técnicas se caracterizan por el alto grado de implicación del alumnado tanto en la búsqueda como en la organización de la información, la elaboración de razonamientos lógicos, la relación y vinculación entre conceptos e ideas, la forma de construir los discursos, etc. Las técnicas participativas grupales que empleamos con mayor asiduidad en el proceso de enseñanza-aprendizaje de nuestra asignatura son: preguntas-respuestas (el alumno elabora en equipo preguntas a las que debe contestar otro grupo de alumnos); debate con guión(discusión por grupos reducidos de un tema de manera pautada y acorde con un guión preestablecido); debate dialéctico (discusión sobre un tema en el que 
cada grupo defiende una posición opuesta al otro u otros grupos); mesa redonda (un grupo de alumnos representan el papel de expertos de un tema, el cual será expuesto al resto del alumnado); panel de expertos (un grupo de alumnos representa el papel de entrevistadores, los cuales elaboran cuestiones a otro grupo de alumnos que adoptan el rol de expertos sobre un tema).

Una buena secuenciación de este proceso de trabajo establecido implica, como actividad prioritaria y previa a la puesta en escena comentada, una acción tutorial que permita el concretar el título del trabajo con los alumnos, acotándolo, convenientemente, para evitar las lagunas intelectuales habituales (vaguedades, hipótesis nada fundamentadas, cuestiones sin interés), ayudándoles a formular un título abordable en los límites del trabajo: por ejemplo, "Tipos de personajes en la revitalización del western crepuscular: Sergio Leone" y no "El western crepuscular"; o "El personaje femenino en las películas de Clint Eastwood" y no "El cine de Clint Eastwood".

Seguidamente, es el brainstorming o el trabajo con preguntas secuenciadas el recurso didáctico que hace que los alumnos se conduzcan hacia un guión convenientemente articulado y construido. $\mathrm{Si}$, por ejemplo, la propuesta de trabajo se centra en analizar la figura del realizador David Lynch, una posible secuencia de preguntas que ayudaría a reconducir la tormenta de ideas hacia un guión con una arquitectura sólida sería: ¿Por qué os interesa David Lynch?, ¿Cuál es su importancia?, ¿En qué tendencia cinematográfica podemos ubicarlo?, ¿Cuáles son sus películas más relevantes?, ¿En qué categoría de director lo encuadraríais?, ¿Cuáles son los rasgos del llamado estilo David Lynch?, ¿Y la temática que trata en sus películas?, ¿Cuáles son las influencias más directas en su carrera como cineasta? ¿Qué relaciones ha mantenido David Lynch con la industria del cine?, ¿Qué tipo de formación tuvo David Lynch?...

Como vemos, el avance en la tormenta de ideas, implica el que los alumnos se orienten hacia referencias importantes para una adecuada elaboración del trabajo: influencias socioculturales en la infancia de David Lynch, su periodo formativo, su carrera profesional, las realizaciones más relevantes, las entrevistas y declaraciones importantes, etc. De este modo, los alumnos evitan las digresiones y esclarecen los puntos básicos del trabajo académico: los objetivos, el objeto de la investigación (tema), los puntos clave en el desarrollo del esquema, las conclusiones, el manejo de las fuentes y las referencias bibliográficas imprescindibles. Así, el alumno logra un conocimiento global sobre los contenidos de la asignatura, amplía su capacidad investigadora y consigue una necesaria madurez intelectual en el área de la Comunicación Audiovisual. Para ello, también, tratamos, que en este trabajo secuenciado de acopio de documentos sobre un determinado autor, un tema o una estética cualquiera, los alumnos hagan siempre uso de los contenidos expresados en la guía docente. 


\section{Las tutorías, piedra angular del sistema}

La lógica secuenciación del proceso didáctico con los trabajo académicos dirigidos implica, también, la preparación de las exposiciones orales de acuerdo con el guión predeterminado, siendo las tutorías el escenario ideal para llevar a buen puerto dicha exposición y el debate posterior que le sigue en el grupo-clase. Este objetivo de personalización en el conocimiento de la asignatura, significa que la tutoría adopte un rol protagonista, dado que, en este escenario privilegiado de intercambio dialéctico alumno-profesor, gestionamos el equilibrio en los avances de la comprensión de los distintos grupos de trabajo establecidos. Para ello, fijamos los horarios de consulta en los mismos días de clase teórica, lo que facilita que, cualquier cuestión o problema suscitado en el transcurso del debate sobre el tema propuesto por el grupo expositor de turno, pueda ser abordado y aclarado convenientemente. Además, el uso constante del aula virtual y del correo electrónico, nos permiten dar respuesta inmediata a las dudas planteadas en estos trabajos académicos en proceso. Por último, ponemos el énfasis en la necesidad de que nuestros alumnos hagan uso de su capacidad para la utilización de las tecnologías y las técnicas comunicativas en los distintos soportes interactivos, mediante el manejo correcto de las herramientas tecnológicas en las diferentes fases del proceso de presentación de su trabajo: búsqueda mediante métodos digitales de documentos en bases de datos, habilidad en el uso de los recursos infográficos, desenvoltura en la variedad de presentación en los distintos soportes digitales y sus aplicaciones interactivas, etc.

\section{Conclusiones}

A lo largo de nuestra exposición y de acuerdo con las recomendaciones que establece la Aneca (2007), hemos utilizado como centro de interés para la acción docente determinadas competencias que son, precisamente, aquellas necesarias para que el profesional flexible se desarrolle armónicamente en la Sociedad del Conocimiento y que, por tanto, están directamente relacionadas con el área general de Ciencias Sociales, tales como: fomento de la capacidad para trabajar en equipo, aprendizaje de la habilidad de ser entendido, el uso del tiempo de una manera eficaz y aprender a secuenciar una determinada actividad. En este sentido, hemos atendido, también, todas las sugerencias que, para el grado en Comunicación Audiovisual se establecen en el Libro Blanco (2004), necesarias para la adquisición de las competencias profesionales establecidas para esta profesión: capacidad de planificación, aprendizaje de la puesta en escena, gestión de recursos técnicos y humanos, organización de la producción audiovisual, etc.

Nuestra metodología, fundamentada en el uso de la comunicación persuasivo-seductora como estrategia didáctica en el aula y centrada en los trabajos académicos dirigidos, facilita que los estudiantes de la asignatura Historia de los medios audiovisuales adquieran el conocimiento de los procesos mediante la práctica diaria con las 
técnicas apropiadas, a la par que, también, se impregnan de la base teórica necesaria para el desarrollo de su futura profesión. Esto hace que, de forma natural, el alumno se familiarice con las dimensiones adecuadas donde radican estas cinco competencias elegidas: lenguaje audiovisual (desarrollo de capacidades como el conocimiento de los códigos y su utilización en el proceso comunicativo, y la capacidad de análisis de los mensajes audiovisuales), tecnología (conocimiento teórico y práctico de las herramientas para la construcción de mensajes audiovisuales), los procesos de producción y programación (capacidad de construir mensajes audiovisuales y conocimiento de sus implicaciones comunicativas), la ideología y los valores (capacidad crítica para analizar los mensajes audiovisuales, comprendiendo ideología y valores implícitos), recepción y audiencia (capacidad crítica para valorar los mensajes audiovisuales como audiencia activa y participativa), la dimensión estética (capacidad de análisis y valoración de los aspectos estéticos, creativos e innovadores de los mensajes audiovisuales).

Además, a lo largo de todo el procedimiento didáctico expuesto, incidimos en el uso permanente de las nuevas tecnologías de la información y la comunicación, trabajando la competencia digital de los alumnos mediante la práctica permanente con las herramientas digitales de la comunicación, lo que incide en el fomento de las siguientes competencias: e-conciencia (comprensión del papel que desempeñan las TIC en el desarrollo de la sociedad), alfabetismo tecnológico (uso diestro de los medios electrónicos), alfabetismo digital (generar y reproducir en diferentes formatos mediante el uso de las TIC, habilidad para conseguir información relevante, y la capacidad para producir y administrar nuevo conocimiento) y alfabetismo mediático (comprender cómo los medios de comunicación tradicionales están transformándose dentro del entorno de los medios electrónicos).

\section{Referencias bibliográficas}

ALBA, C.(2005). La viabilidad de las propuestas metodológicas para la aplicación del crédito europeo por parte del profesorado de las universidades españolas vinculadas a la utilización de las TIC en la docencia y la investigación. Madrid: Dirección General de Universidades. Programa de Estudios y Análisis. Disponible en w.w.w.mec.es/univ/html/informes/estudios_analisis/resultados_2004/ ea0042/EA-2004-0042ALBA-2-InformeGlobal.pdf. [3-09-2013].

ANECA(2004). Libro Blanco Títulos de grado en comunicación. Agencia Nacional de evaluación de la Calidad y Acreditación. Disponible en www.aneca.es/var/ media/150336/libroblanco_comunicacion_def.pdf. [18-09-2013].

ANECA(2007). El profesional flexible en la Sociedad del Conocimiento. Madrid.

BAINBRIDGE, W.(2007). "The scientific research potencial of virtual words". En: Science, ${ }^{\circ} 37$, p. $472-476$.

BARNETT, R.(2001). Los límites de la competencia, el conocimiento, la educación superior y la sociedad. Barcelona: Gedisa. 
CANTOS CEBALLOS, A.(2013). "Cine y alfabetización audiovisual: el análisis del filme como agente activo de comunicación para la educación ciudadana", En Razón y Palabra, $\mathrm{n}^{\mathrm{o}}$ 82. Disponible en www.razonypalabra.org.mx/N/N82/ V82/04_Cantos_V82.pdf [2-10-2013].

CARTER, R.(2002). El nuevo mapa del cerebro. Barcelona: RBA.

DELORS, J. et al(1996). La educación encierra un tesoro, Informe a la UNESCO de la Comisión Internacional sobre la Educación para el Siglo XXI. París: Santillana, Ediciones, UNESCO.

GONZÁLEZ, J. Y WAGENAAR, R.(2003). Tuning Educational Structures in Europe. Bilbao: Universidad de Deusto y Universidad de Groningen.

GUTERL, F. (2002). "What Freud Got Right. Science and Tecnology". En: Newsweek, $\mathrm{n}^{\mathrm{o}} 11$, p. $54-55$.

HUÉ, GARCÍA, C. (2008). Competencias genéricas y transversales de los titulados universitarios. Zaragoza: Instituto de Ciencias de la Educación(ICE), Universidad de Zaragoza.

JESSUP, G.(1991). Outcomes NVQs and the emerging model of education and training. London: Falmer Press.

LEDOUX, J.(2002). Synaptic Self. How Our Brains Become Who We Are. Nueva York: Viking Press.

MOLINÉ, M.(2000): La fuerza de la publicidad. Madrid: Mc Graw-Hill/Interamericana de España.

MURGA MENOYO, Ma A Y QUICIOS GARCÍA Ma del P.(2006). La Reforma en la Universidad. Cambios exigidos por la nueva Europa. Madrid: Dyckinson.

RYCHEN, D. Y TIANA, A.(2004). Developing key competencias in education: some lessons from international and nacional experience. París: UNESCO.

RUÉ DOMINGO, J.(2007). Enseñar en la Universidad. El EEES como reto para la educación superior. Madrid: Narcea.

RUIZ DEL OLMO, F.J.(2009): "Conocimiento en la nube: características sociocomunicativas del cloud computing". En Razón y Palabra, $\mathrm{n}^{\circ} 73,1-16$. Disponible en w.w.w.razonypalabra.org.mx/n/N73/15RuizdelOlmo_V73.pdf. [5-09-2013].

SALINAS, J., AGUADED, J. Y CABERO, J.(2004). Tecnologías para la Educación. Diseño, producción y evaluación de medios para la formación docente. Mallorca: Universidad de las Islas Baleares.

SEALE, J.K.(2006). E-learning and disability in higher education: Accesibility research and practice. Abingdon: Routledge.

SHEELY, K. Y BUCKNALL, S.(2008). "How is technology seen in young people's visions of future education systems". En: Learning, Media and Technology 33, no 4 , p. 101-114.

TUNING(2007). Tuning Educational Structures in Europe.Programme Education and Culture Sócrates-Tempus. Brussels: European Conmission-Directorate General for Education and Culture.

VAZ PERES, L.M. Y ESPERÓN PORTO, T.M.(2006). Tecnologías de educaçao. Tecendo relaçoes entre imaginario, corporeidade e emoçoes. Sao Paulo: Junqueira \& Marín Editores. 


\section{El autor}

Antonio Cantos Ceballos es profesor Titular del Departamento de Comunicación Audiovisual y Publicidad de la Facultad de Ciencias de la Comunicación de la Universidad de Málaga. Sus línea de investigación se centra en el estudio del cine y el teatro con temas que versan sobre la improvisación creativa, el teatro aplicado a la enseñanza o el juego dramático del actor en el cine y el teatro. Algunas de sus últimas publicaciones son: Creatividad expresiva en el arte del actor. Ejercicios prácticos y propuestas para el trabajo de improvisación (2003); "Cine virtual y presencialidad teatral: El cine electrónico de Coppola y sus imbricaciones en la consolidación del género (Peter Jackson)", Revista Iconol4 (2012); Quiero ser un actor de cine: guía práctica para construir un personaje inolvidable (2013), "Cine y alfabetización audiovisual: el análisis del filme como agente activo de comunicación para la educación ciudadana”, Revista Razón y Palabra (2013). 